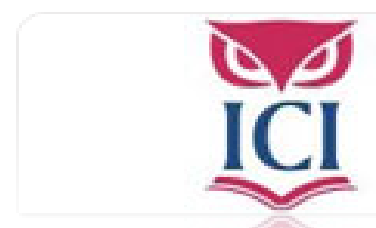

IUS. Revista del Instituto de Ciencias Jurídicas de Puebla A.C.

ISSN: $1870-2147$

revista.ius@hotmail.com

Instituto de Ciencias Jurídicas de Puebla A. C.

México

Bernardo San José, Alicia

LA RESTRICCIÓN DE LOS DERECHOS FUNDAMENTALES EN LAS DILIGENCIAS DE INVESTIGACIÓN DEL PROCESO PENAL Y LAS EXIGENCIAS DERIVADAS DEL PRINCIPIO DE PROPORCIONALIDAD

IUS. Revista del Instituto de Ciencias Jurídicas de Puebla A.C., núm. 24, 2009, pp. 7-26 Instituto de Ciencias Jurídicas de Puebla A. C.

Puebla, México 


\title{
LA RESTRICCIÓN DE LOS DERECHOS FUNDAMENTALES EN LAS DILIGENCIAS DE INVESTIGACIÓN DEL PROCESO PENAL Y LAS EXIGENCIAS DERIVADAS DEL PRINCIPIO DE PROPORCIONALIDAD \\ THE RESTRICTION OF FUNDAMIENTAL RIGHTS IN CRIMINAL INVESTIGATION PROCEDURES AND THE REQUIREMENTS ARISING FROM THE PRINCIPLES OF PROPORTIONALITY
}

\author{
Alicia Bernardo San José
}

\section{RESUMEN}

A partir del reconocimiento de que el proceso penal demanda la restricción de determinados derechos fundamentales, en aras de lograr el esclarecimiento de los hechos sujetos a investigación y sus autores, se analiza el alcance que puede tener esta restricción, bajo el cumplimiento de los requisitos de justificación teleológica, habilitación legal para ello, resolución judicial que lo autorice, apariencia del delito y de proporcionalidad. Por lo significativo que resultan, se analizan las medidas de intervención de comunicaciones privadas, tanto telefónicas como postales, asi como el registro de libros y papeles, la entrada y registro en lugar cerrado y la infiltración policial.

PALABRAS CLAVE: Proceso penal, enjuiciamiento criminal, agente encubierto, infiltración policial, entrada, registro, intervención de comunicaciones

\begin{abstract}
Upon recognition that criminal proceedings calls for the restriction of certain fundamental rights, in order to clarify facts under investigation and perpetuators, discusses the scope that this restriction may have, under the requirement of teleological justification, legal authorization for it, legal determination, judicial resolution that authorizes it, the crime appearance and proportionality. As for the implication that results from it, interference measures are analyzed private communications, telephone and mail, as well as books and paper records, the entering and searching of an enclose place and undercover work by police.
\end{abstract}

KEY WORDS: Criminal process, criminal procedure, undercover agent, police undercover, search, communications interception

* Profesora de derecho procesal de la Universidad Complutense de Madrid. Recibido el 20.08.2009. Aceptado: 23.10.2009. 


\section{SUMARIO}

1. Introducción

2. Infiltración policial y agente encubierto

3. La entrada y registro en lugar cerrado

4. El registro de libros y papeles

5. La intervención de las comunicaciones privadas

A) La intervención de las comunicaciones telefónicas

B) La intervención de las comunicaciones postales

\section{Introducción}

En todo proceso penal puede ser necesario restringir o limitar los derechos fundamentales del imputado, y a veces de terceras personas. Esta necesidad se aprecia, sobre todo, en dos terrenos distintos:

En primer término, una correcta investigación criminal puede requerir la limitación de algún derecho fundamental del imputado. La instrucción penal tiene como objetivo fundamental la averiguación de la realidad de los hechos y la identificación de las personas que hayan participado en ellos (arts. 299 y 777.1 LECrim). Y es bastante frecuente que en el curso de esa actividad instructora dicha averiguación de la verdad exija la restricción de algún derecho fundamental, por lo que se produce una tensión entre el deber de los Poderes Públicos de realizar una eficaz represión de las conductas punibles y la correlativa protección de los derechos fundamentales del imputado que el Estado debe, igualmente, procurar.

En segundo término, también puede ser necesaria la restricción de derechos fundamentales del imputado para asegurar su presencia física en el proceso penal durante todas sus fases, es decir, que se encuentre en todo momento a disposición de la administración de justicia. Y ello se logra, quiérase o no, a través de las limitaciones de su derecho a la libertad. De hecho, la adopción de medidas cautelares personales supone el punto más crítico del difícil equilibrio entre los dos intereses sobre los que gira el proceso penal: el respeto a los derechos fundamentales del imputado y el interés de persecución penal.

Que el Estado, en el marco del proceso penal, esté autorizado a limitar derechos fundamentales del imputado e incluso de terceras personas, no significa que pueda hacerlo de cualquier manera. Acerca de las diligencias que suponen una limitación de derechos fundamentales, el Tribunal Constitucional ha elaborado una doctrina, según la cual la adopción de tales diligencias está supeditada, en todo caso, al cumplimiento de una serie de requisitos, tanto externos o 
formales, como internos o de contenido. ${ }^{1}$ Entre los primeros se encuentran la justificación teleológica, la habilitación legal y la autorización judicial motivada; entre los segundos, la existencia de una apariencia delictiva y la proporcionalidad en sentido amplio de la medida restrictiva de los derechos fundamentales. ${ }^{2}$

$\left.1^{\circ}\right)$ Justificación teleológica: Toda medida restrictiva de un derecho fundamental sólo se justifica si se orienta hacia un fin constitucionalmente legítimo y socialmente relevante. En el caso del proceso penal, el interés público propio de la investigación de un delito y, más concretamente, la determinación de hechos relevantes para la investigación penal del mismo son, desde luego, causa legitima que puede justificar la realización de una medida limitativa de un derecho fundamental.

$2^{\circ}$ ) Habilitación legal expresa: Cualquier restricción de un derecho fundamental debe estar prevista y regulada por una ley. ${ }^{3}$ Así lo exige el artículo 53.1 CE, según el cual "sólo por ley" podrá regularse el ejercicio de tales derechos y libertades fundamentales. En nuestro ordenamiento, además, esta ley ha de ser orgánica, pues como establece el artículo 81.1 cE, "son leyes orgánicas las relativas al desarrollo de los derechos fundamentales y las libertades públicas..."

Esta reserva de ley desempeña una doble función: de una parte, asegura que los derechos que la Constitución atribuye a los ciudadanos no se vean afectados por ninguna injerencia estatal no autorizada por sus representantes; $y$, de otra, en un ordenamiento jurídico como el nuestro en el que los jueces y magistrados se hallan sometidos únicamente al imperio de la ley constituye, en definitiva, el único modo efectivo de garantizar las exigencias de seguridad jurídica en el ámbito de los derechos fundamentales y las libertades públicas. ${ }^{4}$

30) Resolución judicial motivada: La decisión de restringir un derecho fundamental debe ser adoptada por un órgano jurisdiccional en el seno de un proceso, sin perjuicio de que la ley pueda autorizar la actuación de la policía judicial cuando concurran razones de urgencia y necesidad. En concreto, el juez

\footnotetext{
${ }^{1}$ Cfr., sin ánimo de exhaustividad, Sstc 37/1989, 120/1990, 7/1994, 66/1995, 35/1996, 54/1996, 55/1996, 56/1996, 170/1996, 207/1996, 67/1997, 33/1999, 141/1999, 184/2003, 146/2006, 89/2006, 26/2006, 170/2008 y 122/2008.

${ }^{2}$ Acerca del "régimen general sobre la restricción de derechos fundamentales en el proceso penal", Cfr., en nuestra doctrina, González-Cuéllar Serrano, N., Proporcionalidad y derechos fundamentales en el proceso penal, Madrid, 1990; Banacloche Palao, J., La libertad personal y sus limitaciones. Detenciones y retenciones en el derecho español, Madrid, 1996, pp. 207 y ss.; más recientemente, GASCÓN INCHAUSTI, F., Infiltración policial y “agente encubierto”, Granada, 2001, pp. 110 y ss. Y González-Cuéllar Serrano, N. (Dir.), Investigación y prueba en el proceso penal, Madrid, 2006 y Riaño Brun, I., La instrucción criminal en el proceso penal, Navarra, 2008.

${ }^{3}$ La necesidad de esa previsión legal ha sido afirmada expresamente por el Tribunal Constitucional respecto de un amplio elenco de derechos fundamentales y libertades públicas. Así, por ejemplo, en relación con el derecho a la intimidad (sstc 37/89, 207/96, 70/02); el derecho a la integridad física (SSTc 120/90, 7/94, 35/96); el derecho a la libertad de expresión (sтc 52/95); el derecho a la libertad personal (sstc 32/87, 86/96, 47/00, 169/01), y el derecho al secreto de las comunicaciones (sstc 49/99, 184/03).

${ }^{4}$ Cfr. stc 49/1999 (Pleno), de 5 de abril.
} 
que ha de otorgar la autorización para la práctica de medidas restrictivas de derechos fundamentales, en el ámbito de la investigación criminal, es el juez de instrucción. ${ }^{5}$

Por otra parte, toda resolución judicial que limite o restrinja el ejercicio de un derecho fundamental ha de estar debidamente motivada, de forma que las razones fácticas y jurídicas de tal limitación puedan ser conocidas por el afectado, ya que sólo a través de la expresión de las mismas se preserva el derecho de defensa y puede hacerse, siquiera sea a posteriori, el necesario juicio de proporcionalidad entre el sacrificio del derecho fundamental y la causa a la que obedece. Si ha de ser, por tanto, resolución judicial motivada, ha de tratarse de un auto.

El deber de motivación de las resoluciones judiciales limitativas de los derechos fundamentales no encuentra su fundamento constitucional en la genérica obligación de motivación de todas las resoluciones judiciales que resulta del derecho a la tutela judicial efectiva (art. 24.1 en relación con el art. $120.3 \mathrm{cE}$ ), ni se satisface, pues, con cualquier forma de motivación que permita conocer la ratio decidendi de la resolución judicial (sSTc 128/1995 y 158/1996). La exigencia de motivación aquí es ante todo un requisito formal de la regla de proporcionalidad, según el cual en las resoluciones limitativas de los derechos fundamentales debe el órgano jurisdiccional plasmar el juicio de ponderación entre el derecho fundamental afectado y el interés constitucionalmente protegido y perseguido, del cual se evidencie la necesidad de la adopción de la medida (ssTc 37/1989 y 7/1994, entre otras).

La motivación de la resolución cumple en todo caso una doble finalidad: posibilita la impugnación de las decisiones de los órganos jurisdiccionales cuando no sean acordes con los posicionamientos de las partes y evita la inseguridad jurídica que se produciría como consecuencia de una arbitraria actuación judicial.

$4^{\circ}$ ) Apariencia delictiva: Las diligencias de investigación restrictivas de derechos fundamentales sólo pueden adoptarse cuando el juez se encuentre con indicios suficientes de que la persona cuyos derechos se han de restringir ha cometido un hecho delictivo concreto. En otros términos, no puede restringirse un derecho fundamental para satisfacer la necesidad genérica de prevenir o descubrir delitos o para despejar las sospechas sin base objetiva que surjan en la mente de los encargados de la investigación penal, por más legítima que sea esta aspiración, pues, de otro modo, se desvanecería la garantía constitucional.

50) Proporcionalidad en sentido amplio: Según doctrina reiterada del Tribunal Constitucional, una exigencia común y constante para la constitucionalidad

${ }^{5}$ Cfr. Gónzález-Cuéllar Serrano, N., Proporcionalidad y derechos fundamentales en el proceso penal, Op. cit., pp. 109 y ss. 
de cualquier medida restrictiva de derechos fundamentales viene determinada por la estricta observancia del principio de proporcionalidad. ${ }^{6}$

Para comprobar si una concreta medida restrictiva de un derecho0 fundamental supera el juicio de proporcionalidad, es necesario constatar si cumple los tres siguientes requisitos o condiciones: si tal medida es susceptible de conseguir el objetivo propuesto (juicio de idoneidad); si, además, es necesaria, en el sentido de que no exista otra medida más moderada para la consecución de tal propósito con igual eficacia (juicio de necesidad); y, finalmente, si la misma es ponderada o equilibrada, por derivarse de ella más beneficios o ventajas para el interés general que perjuicios sobre otros bienes o valores en conflicto (juicio de proporcionalidad en sentido estricto) [sTc 207/1996 (Sala Primera), de 16 de diciembre].

Veamos estos tres requisitos con más detenimiento.

El requisito de la idoneidad o adecuación consiste en que el medio que se emplee para restringir el derecho fundamental debe ser apropiado al fin constitucionalmente legítimo que se pretende, es decir, debe contribuir significativamente a obtener el resultado apetecido. ${ }^{7}$ En el marco del proceso penal, este requisito se cumplirá si la medida propuesta sirve objetivamente para determinar los hechos que constituyen el objeto del proceso penal.

El segundo requisito es la necesidad o subsidiaridad, también denominada alternativa menos gravosa o intervención mínima, que supone que el medio seleccionado para alcanzar el fin no pueda ser suplido por otro igualmente eficaz, pero que no restrinja el derecho fundamental o que lo haga de una manera menos gravosa. Este requisito obliga a comparar la medida restrictiva que se pretende adoptar con otras posibles, debiendo acogerse aquella que sea menos lesiva para los derechos de los ciudadanos. ${ }^{8}$

Como ha señalado el Tribunal Constitucional, "para que tal exigencia concurra en una determinada medida limitativa de los derechos fundamentales es preciso que su opción se revele objetivamente imprescindible para el aseguramiento de un bien o interés constitucionalmente relevante, lo que, trasladado al ámbito particular del proceso penal ha de habilitar a la autoridad judicial a decretar tales medidas únicamente cuando su adopción sea indispensable para asegurar la defensa del interés público que se pretende defender mediante el

\footnotetext{
${ }^{6}$ Cfr. González-Cuéllar Serrano, N., Proporcionalidad y derechos fundamentales en el proceso penal, op. cit., pp. 153-154; Pedraz Penalva, E., "El principio de proporcionalidad y su configuración en la jurisprudencia del Tribunal Constitucional y literatura especializada alemanas" (con Ortega Benito, V.), Poder Judicial, No. 17, pp. 83 y ss.

${ }^{7}$ Cfr. González-Cuéllar Serrano, N., Proporcionalidad y derechos fundamentales en el proceso penal, Op. cit., pp. 154 y ss.

${ }^{8}$ Cfr. González-CuÉllar Serrano, N., Proporcionalidad y derechos fundamentales en el proceso penal, Op. cit., p. 189.
} 
ejercicio del ius puniendi (stc 37/1989, F.J. 8. ${ }^{\circ}$ ). En suma, pues, una medida de instrucción penal restrictiva de los derechos fundamentales habrá de reputarse necesaria cuando de su resultado pueda depender el ejercicio del ius puniendi, lo que tan sólo acontecerá cuando su puesta en práctica permita acreditar, desde un punto de vista objetivo, la existencia de alguno o algunos de los hechos constitutivos del tipo delictivo objeto de investigación y, desde el subjetivo, la participación del imputado en los mimos" (sтс 207/1996).

Por último, la proporcionalidad en sentido estricto o prohibición de exceso consiste en la comprobación de que la medida restrictiva de derechos fundamentales, aun siendo idónea y necesaria, no conlleva una lesión excesiva sobre el derecho afectado, esto es, de que se da una correlación adecuada entre la intensidad del ataque al derecho y el resultado que con ello se obtiene. ${ }^{9}$ Entre los factores o elementos de juicio que deben tenerse en cuenta a la hora de comprobar la proporcionalidad de la medida pueden tenerse en cuenta, entre otros, los siguientes: la gravedad de los delitos para cuya investigación se autoriza, la intensidad de los indicios de criminalidad y la duración y utilidad de la medida.

Expondremos a continuación las diligencias de investigación restrictivas de derechos fundamentales previstas en el título vil del libro $n$ de la Ley de Enjuiciamiento Criminal: la infiltración policial y el agente encubierto, la entrada y registro en lugar cerrado, el registro de libros y papeles, la detención y apertura de la correspondencia escrita y telegráfica y la intervención de las comunicaciones telefónicas.

\section{Infiltración policial y agente encubierto}

La Lo 5/1999, de 13 de enero, de modificación de la Ley de Enjuiciamiento Criminal en materia de perfeccionamiento de la acción investigadora relacionada con el tráfico ilegal de drogas y otras actividades ilícitas graves, introdujo en la LECrim el artículo 282-bis, que incorpora a nuestro proceso penal un nuevo instrumento para la represión de la delincuencia organizada: la infiltración de agentes policiales encubiertos. ${ }^{10}$

\footnotetext{
${ }^{9}$ González-Cuéllar Serrano, N., Proporcionalidad y derechos fundamentales en el proceso penal, Op. cit., pp. 225 y ss.

${ }^{10}$ Para la redacción de este epígrafe hemos seguido la excelente obra de Gascón InCHAUsTI, F., Infiltración policial y "agente encubierto", Granada, 2001. Vid., también, Delgado Martin, J., "El proceso penal ante la criminalidad organizada. El agente encubierto", Actualidad Penal, No. 1, 2000, pp. 1-28; López BARJA de Quiroga, J., "El agente encubierto", La Ley, No. 4778, 20 de abril de 1999; Moreno Catena, V., "Los agentes encubiertos en España", Otrosí (ICAM), 1999, No. 10, págs. 40-42; Pérez ARroYo, M.R., "La provocación de la prueba, el agente provocador y el agente encubierto: la validez de la provocación de la prueba y del delito en la lucha contra la criminalidad organizada desde el sistema de pruebas prohibidas en el derecho penal y procesal penal", La Ley, Nos. 4987, 4988 y 4999, 8-10 de febrero de 2000;
} 
La infiltración policial es una técnica para la investigación procesal penal cuya finalidad es suministrar a las autoridades de persecución penal informaciones de relevancia y lo suficientemente fiables como para preparar un juicio oral. El agente encubierto, por su parte, es el instrumento elegido por el legislador al servicio de esta técnica consistente en la entrada de un funcionario de la Policía Judicial -que actúa bajo una identidad supuesta facilitada por el Ministerio del Interior- en el seno de una organización delictiva para obtener información referida a los integrantes de la organización y a las actividades delictivas llevadas a cabo por ellos que sirva como prueba de cargo en un proceso penal.

El ámbito de utilización de esta técnica de investigación criminal se circunscribe al de la "delincuencia organizada", entendida como la que se produce por la asociación de tres o más personas para realizar de forma permanente o reiterada, conductas que tengan como fin cometer alguno de los siguientes delitos: secuestro de personas; prostitución; ciertos delitos contra el patrimonio y el orden socioeconómico; delitos contra los derechos de los trabajadores; tráfico de especies de flora o fauna amenazada; tráfico de material nuclear y radiactivo; delitos contra la salud pública; delitos de falsificación de moneda; tráfico y depósito de armas, municiones o explosivos; delitos de terrorismo; $y$, finalmente, delitos contra el patrimonio histórico (art. 282-bis 4 LECrim).

La técnica de la infiltración policial se funda en el engaño y en el abuso de confianza por parte del Estado frente a sus ciudadanos: no sólo se oculta la condición de policía del agente infiltrado, sino que se le proporciona una cobertura o identidad falsa que resulte idónea para obtener la confianza de los miembros de una organización criminal y lograr introducirse en ella en busca de información. Además, supone la tolerancia y la comisión de delitos por parte del Estado: de un lado, se demora la reacción pública ante la constancia de hechos aparentemente delictivos y, de otro, el agente policial infiltrado, quiérase o no, va a participar en la comisión de ciertos delitos. Por último, la entrada y participación en la vida negocial de un sujeto que realmente no existe (el agente encubierto) pone en peligro la seguridad del tráfico jurídico privado. ${ }^{11}$

Llegados a este punto, debemos plantearnos si estamos ante una diligencia sumarial restrictiva de derechos fundamentales. En este sentido, puede sostenerse que la infiltración policial lesiona en todo caso el derecho fundamental al libre desarrollo de la personalidad reconocido en el artículo 10.1 cE que proclama la dignidad humana y el libre desarrollo de la personalidad como fundamentos

RIFA SOLER, J.M., "El agente encubierto o infiltrado en la nueva regulación de la LECrim", Poder Judicial, No. 55, 1999, pp. 157 y ss; Rodriguez Fernández, R., "Comentarios a la to 5/1999, de 13 de enero: la 'entrega vigilada' y el agente encubierto", Actualidad Jurídica Aranzadi, No. 380, 4 de marzo de 1999, pp. 1 y ss.

${ }^{1 C}$ Cfr. Gascón Inchausti, F., Infiltración policial y "agente encubierto", Op. cit., pp. 86-91. 
del orden político y de la paz social. Que el Estado deliberadamente promueva y fomente la confianza de un sujeto, con la finalidad de obtener determinada información que, directa o indirectamente, se utilizará en su contra, como prueba de cargo, en un proceso penal, supone una lesión de este derecho, en la medida en que atenta contra la creación de vínculos de confianza entre las personas, confianza que está en la base de la comunicación humana, sin la cual no es posible el desarrollo de la personalidad. Como señala Gascón INCHAUSTI, "si los ciudadanos asumiéramos como normal o posible que, en cualquier momento, alguna persona de nuestro entorno pudiera ser un agente policial encubierto que nos está engañando y que pretende obtener información a través de nosotros, ¿serian nuestras relaciones sociales idénticas?; ¿acaso no se rompería una de las bases sobre las que se asienta la convivencia en un estado de derecho?" 12

También pueden verse afectados de forma negativa por la actuación de un agente encubierto los derechos fundamentales a la intimidad (art. $18.1 \mathrm{cE}$ ), a la inviolabilidad del domicilio (art. $18.2 \mathrm{cE}$ ), y al secreto de las comunicaciones (art. $18.3 \mathrm{CE}$. En efecto, el engaño de que se sirve el Estado a través de su agente encubierto le permite acceder a informaciones y a esferas íntimas del imputado y de terceras personas, que no habrían permitido ese acceso de conocer su identidad real. También puede servirse de la infiltración para lograr la entrada en ciertos lugares que tienen la consideración de domicilio y que, en otro caso, le resultarian infranqueables sin previa orden judicial, así como para presenciar conversaciones ajenas.

Finalmente, la actividad de los agentes infiltrados puede comprometer el derecho a no declarar contra uno mismo y a no confesarse culpable (art. $24.2 \mathrm{cE}$ ), cuando a través de ella se logra que el imputado formule declaraciones incriminatorias que pueden tener acceso a un juicio oral y servir en él de fundamento a una sentencia de condena. ${ }^{13}$

Tratándose, por tanto, de una diligencia de investigación que puede atentar contra el contenido de ciertos derechos fundamentales, en especial, contra el derecho al libre desarrollo de la personalidad, la infiltración policial sólo puede considerarse constitucionalmente legítima cuando esté legalmente prevista y la adopte de forma motivada un juez en presencia de indicios suficientes de criminalidad, considerándola como adecuada, necesaria y proporcionada a la luz de las circunstancias del caso concreto.

En cuanto a su régimen legal, podemos destacar lo siguiente:

a) La autorización para proceder a una infiltración policial, cuya duración

\footnotetext{
${ }^{12} \mathrm{Cfr}$. Gascón Inchausti, F., Infiltración policial y “agente encubierto", Op. cit., p. 96.

${ }^{13} \mathrm{Cfr}$. Gascón Inchausti, F., Infiltración Policial y "agente encubierto”, Op. cit., pp. 92-109.
} 
máxima será de seis meses - prorrogables por periodos iguales-, puede concederla el juez de instrucción competente o el Ministerio Fiscal, dando cuenta inmediata al juez.

b) La información que vaya obteniendo el agente encubierto deberá ser puesta a la mayor brevedad posible en conocimiento de quien autorizó la investigación.

c) El agente podrá mantener la identidad falsa cuando testifique en el proceso, siempre que así se acuerde mediante resolución judicial motivada, siéndole también de aplicación lo previsto en la Ley Orgánica 19/1994, de 23 de diciembre, de protección a testigos y peritos en causas criminales.

d) Las tareas investigadoras del agente encubierto no pueden suponer restricciones a los derechos fundamentales de los ciudadanos, más allá de lo que ya de por sí significa la infiltración, salvo que su práctica se sujete a los requisitos legales y constitucionales establecidos.

e) El agente estará exento de responsabilidad criminal por aquellas actuaciones que sean consecuencia necesaria del desarrollo de la investigación, siempre que guarden la debida proporcionalidad con la finalidad de la misma y no constituyan una provocación al delito.

Para poder proceder penalmente contra el mismo por las actuaciones realizadas a los fines de la investigación, el juez competente para conocer la causa deberá, tan pronto tenga conocimiento de la actuación de algún agente encubierto en la misma, requerir informe relativo a tal circunstancia de quien hubiere autorizado la identidad supuesta, en atención al cual resolverá lo que a su criterio proceda.

\section{La entrada y registro en lugar cerrado}

La entrada y registro en lugar cerrado se regula en los artículos 545 a 572 LECrim. Se trata de una diligencia de investigación que consiste en la penetración en un determinado recinto aislado del exterior, con la finalidad de buscar y recoger fuentes de investigación o aprehender a la propia persona del procesado. En realidad, esta diligencia se compone de dos actuaciones diferentes: de un lado, la entrada, que puede utilizarse de forma autónoma cuando se pretende proceder a la detención del imputado y, de otro lado, el registro, que presupone una entrada previa y cuya finalidad es acceder a las fuentes de prueba cuando se sospecha la presencia de objetos útiles para el descubrimiento y comprobación del delito. ${ }^{14}$

${ }^{14}$ Cfr. Cabezudo Bajo, M.J., La protección del domicilio, Valencia, 2004; Hinojosa Segovia, R., La diligencia de entrada y registro en lugar cerrado en el proceso penal, Madrid, 1996; FIGUEROA NAVARRO, C., Entrada y registro en domicilio, Madrid, 1994; González-Trevijano Sánchez, P.J., La inviolabilidad del domicilio, Madrid, 1992; González-Cuéllar Serrano, N., "Entrada y registro en el domicilio", Cuadernos de Derecho Judicial, CGPJ, 1993, xxIx, pp. 117-130; DE 
En cuanto a los lugares susceptibles de entrada y registro, la ley distingue entre domicilio particular y edificios y lugares públicos, sometiendo la entrada y registro de cada uno de ellos a requisitos específicos.

Se reputan domicilio, conforme al artículo 554 LECrim: $1^{\circ}$ : los palacios reales, estén o no habitados por el Monarca al tiempo de entrada o registro; $2^{\circ}$ : el edificio o lugar cerrado, o la parte de él destinada principalmente a la habitación de cualquier español o extranjero residente en España y de su familia; $3^{\circ}$ : los buques nacionales mercantes. Se consideran edificios o lugares públicos, según el artículo $547 \mathrm{LECrim:} 1^{\circ}$ : los que estuvieren destinados a cualquier servicio oficial, militar o civil del Estado, de la provincia o del municipio, aunque habiten allí los encargados de dicho servicio o los de la conservación y custodia del edificio o lugar; $2^{\circ}$ : los que estuvieren destinados a cualquier establecimiento de reunión o recreo, fueren o no lícitos; $3^{\circ}$ : cualesquiera otros edificios o lugares cerrados que no constituyeren domicilio de un particular con arreglo a lo dispuesto en el artículo 554; $4^{\circ}$ : los buques del Estado.

La entrada y registro domiciliario supone la limitación del derecho fundamental a la inviolabilidad del domicilio. La Constitución española dispone en el artículo 18.2 que "el domicilio es inviolable. Ninguna entrada o registro podrá hacerse en él sin consentimiento del titular o resolución judicial, salvo en caso de flagrante delito".

La protección constitucional del domicilio en el artículo 18.2 cE se concreta en dos reglas distintas. La primera se refiere a la protección de su "inviolabilidad", en cuanto garantía de que dicho ámbito espacial de privacidad de la persona elegido por ella misma resulte "exento de" o "inmune a" cualquier tipo de invasión o agresión exterior de otras personas o de la autoridad pública, incluidas las que puedan realizarse sin penetración física en el mismo, sino por medio de aparatos mecánicos, electrónicos u otros análogos. La segunda establece la interdicción de dos de las formas posibles de injerencia en el domicilio, esto es, su entrada y registro, disponiéndose que, fuera de los casos de flagrante delito, sólo son constitucionalmente legítimos la entrada o el registro efectuados con consentimiento de su titular o resolución judicial; de modo que la mención de las excepciones a dicha interdicción, admitidas por la Constitución, tiene carácter taxativo (sтc 22/1984, de 17 de febrero). ${ }^{15}$

El concepto de domicilio, con base en la jurisprudencia constitucional, debe entenderse en sentido amplio. Según el Tribunal Constitucional la noción de

Lorenzo Martinez, F., "Diligencia de entrada y registro", en La prueba en el proceso penal, Madrid, 1992, pp. 511 y sS; Franco ARIAS, J., "La entrada en lugar cerrado", Justicia, III, 1988, pp. 581 y ss.; Garcia MaCho, R., "La inviolabilidad del domicilio", REDA, No. 32, 1982, pp. 855 y ss.

${ }^{15}$ Cfr. sstc 136/2000, de 29 de mayo y 10/2002, de 17 de enero. 
domicilio amparada por el artículo 18.2 CE no se refiere de un modo exclusivo al lugar de residencia habitual, al establecimiento definitivo y permanente de las personas, sino a todo lugar cerrado en el que se desarrolle de un modo u otro una actividad privada, con ánimo de exclusión de terceros; ${ }^{16}$ se tutela, en definitiva, cualquier espacio físico en el que se despliegue el ámbito de privacidad de las personas, con independencia de que tenga carácter habitual, permanente o estable, o por el contrario, transitorio, temporal o accidental.

En este sentido, y sin ánimo de exhaustividad, ${ }^{17}$ tienen la condición de domicilio: una vivienda, aun cuando en el momento del registro no esté habitada (sTC 94/1999); las roulottes o caravanas (sTs de 17 de marzo de 1993 -RA 2330-); las chabolas o infraviviendas, siempre que se habite en ellas (STS de 19 de octubre de 1994 -RA 8031-); el domicilio de las personas jurídicas privadas (Sтс 137/1985) y el de las personas jurídicas públicas (sтс 68/1988); los despachos profesionales (STEDH de 16 de diciembre de 1992), así como las habitaciones de hotel (sTc 10/2002, de 17 de enero). ${ }^{18}$

En el marco del proceso penal, la autoridad pública sólo podrá entrar y registrar un domicilio si se da alguno de los tres siguientes presupuestos:

$1^{\circ}$ ) Consentimiento del titular. La autoridad que vaya a realizar la diligencia debe solicitar el consentimiento del legítimo titular del domicilio de manera expresa y formal. Además, el consentimiento, que puede ser expreso, tácito o presunto (art. $551 \mathrm{LECrim}$ ), debe prestarse por una persona capaz (art. 566 LECrim), y debe ser consciente y libre. ${ }^{19}$

$\left.2^{\circ}\right)$ Autorización judicial. En defecto de consentimiento del titular del domicilio, podrá el juez instructor decretar la entrada y registro mediante auto debidamente motivado, cuando hubiere indicios de encontrarse allí el sospe-

\footnotetext{
${ }^{16}$ Según el Tribunal Constitucional "la idea de domicilio que utiliza el artículo 18 de la Constitución no coincide plenamente con la que se utiliza en materia de derecho privado y en especial en el artículo 40 del Código Civil como punto de localización de la persona o lugar de ejercicio por ésta de sus derechos y obligaciones". El concepto constitucional de domicilio "tiene mayor amplitud que el concepto juridico privado o juridico-administrativo" (STC 22/84), y "no admite concepciones reduccionistas como las que lo equiparan al concepto jurídico-penal de morada habitual o habitación" (sтc 94/99).

${ }^{17}$ Cfr. Magro Servet, V., "Casuística sobre el concepto penal de domicilio en la diligencia de entrada y registro", $L a$ Ley, No. 5479, pp. 1-12.

${ }^{18}$ En esta sentencia, el Tribunal Constitucional declaró la inconstitucionalidad del art. 557 LECrim según el cual, "las tabernas, casa de comidas, posadas y fondas no se reputarán como domicilio de los que se encuentren o residan en ellas accidental o temporalmente, y lo serán tan sólo de los taberneros, hosteleros, posaderos y fondistas que se hallen a su frente y habiten alli con sus familias en la parte del edificio a este servicio destinada". En palabras de este Tribunal, "las habitaciones de hoteles pueden constituir domicilio de sus huéspedes, ya que, en principio, son lugares idóneos, por sus propias características, para que en las mismas se desarrolle la vida privada de aquéllos... (F.J. octavo)". Vid., Bernardo San José, A., "Inconstitucionalidad del art. 557 de la Ley de Enjuiciamiento Criminal, relativo a la entrada y registro de las habitaciones de hotel", Tribunales de Justicia, diciembre, 2002, pp. 86-97.

${ }^{19} \mathrm{Cfr}$. Hinojosa Segovia, R., La diligencia de entrada y registro en lugar cerrado en el proceso penal, Op. cit., pp. 74 a 81
} 
choso o efectos o instrumentos del delito, o libros, papeles u otros objetos que puedan servir para su descubrimiento y comprobación (art. 546 LECrim). ${ }^{20}$

En el auto de entrada y registro en el domicilio de un particular, el juez expresará el edificio o lugar cerrado en que haya de verificarse, si tendrá lugar tan sólo de día y la autoridad o funcionario que los haya de practicar (art. 558 LECrim). También expresará, según la jurisprudencia, las circunstancias personales del titular del domicilio (STS 5 de julio de 1993 -RA 5872-), ${ }^{21}$ el delito que se investiga (STC 22/1984, de 17 de febrero), la fecha para llevar a cabo la diligencia (ATS de 12 de enero de 1994 -RA 475-), y las firmas del juez y del secretario (STS de 23 de junio de 1992 -RA 5831-). ${ }^{22}$

$\left.3^{\circ}\right)$ Delito flagrante. Sin necesidad de consentimiento del titular ni de resolución judicial, la entrada y registro puede llevarse a cabo en el supuesto de delito flagrante. Para que haya flagrancia entiende la jurisprudencia que han de concurrir tres condiciones: a) que exista una actualidad en la comisión del delito; b) que sea evidente la participación del sujeto en los hechos delictivos; c) que se dé una necesidad urgente de que intervenga la policía.

Tras la entrada en vigor de la Ley Orgánica 38/2002, de 24 de octubre, de reforma parcial de la LECrim, sobre procedimiento para el enjuiciamiento rápido e inmediato de determinados delitos y faltas, y de modificación del procedimiento abreviado, contamos ya con la definición de delito flagrante del artículo 795.1.1.a LECrim, según el cual "Se considerará delito flagrante el que se estuviere cometiendo o se acabare de cometer cuando el delincuente sea sorprendido en el acto. Se entenderá sorprendido en el acto no sólo al delincuente que fuere detenido en el momento de estar cometiendo el delito, sino también al detenido o perseguido inmediatamente después de cometerlo, si la persecución durare o no se suspendiere mientras el delincuente no se ponga fuera del inmediato alcance de los que le persiguen. También se considerará delincuente in fraganti aquel a quien se sorprendiere inmediatamente después de cometido un delito con efectos, instrumentos o vestigios que permitan presumir su participación en él".

En cuanto a la práctica de esta diligencia, se realizará preferentemente de día, o de noche si la urgencia lo requiere (art. 550 LECrim). Si llegada la noche no hubiera finalizado se suspenderá la diligencia, a salvo el consentimiento del interesado o cuando el juez así lo autorice (art. 570 LECrim). En su práctica

\footnotetext{
${ }^{20}$ Cfr. Hinojosa Segovia, R., La diligencia de entrada y registro en lugar cerrado en el proceso penal, Op. cit., pp. 81 a 99.

${ }_{21}^{21}$ En el mismo sentido, sSTs de 26 de noviembre de 1994 (RA 8975); 27 de enero de 1995 (RA 152); 3 de marzo de 1995 (RA 1791).

${ }^{22}$ En el mismo sentido, SSTS de 2 de marzo de 1993 (RA 1895) y 29 de octubre de 1993 (RA 8139).
} 
se evitarán las inspecciones inútiles, procurando no perjudicar ni importunar al interesado más de lo necesario, y se adoptarán todo género de precauciones para no comprometer su reputación y respetando sus secretos si no interesasen a la instrucción (art. 552 LECrim).

Si la diligencia de entrada y registro hubiese sido acordada por el juez por medio de un auto, se notificará al interesado inmediatamente, o lo más tarde dentro de las 24 horas de haberse dictado. En su práctica podrán intervenir las siguientes personas: a) el juez instructor, que puede delegar en otro juez o en cualquier autoridad o agente de la policía judicial (art. 563 LECrim); b) el secretario judicial, que puede ser sustituido por oficial habilitado (art. 569 LECrim); c) los agentes de policía judicial que sean precisos y d) el interesado o su representante o un familiar mayor de edad o, en su defecto, dos testigos cualesquiera (art. 569 LECrim).

De todo lo actuado se levantará acta por el secretario u oficial y la firmarán todos los intervinientes.

En caso de que el registro se practicara sin autorización judicial previa (casos de flagrancia o consentimiento del titular), la diligencia tendrá un carácter exclusivamente policial. Del registro efectuado se dará cuenta inmediata al juez competente, con indicación de las causas que lo motivaron y de los resultados obtenidos en el mismo, con especial referencia a las detenciones que, en su caso, se hubieran practicado. Asimismo, se indicarán las personas que hayan intervenido y los incidentes ocurridos (art. 553 II LECrim).

Todas las pruebas obtenidas en un registro practicado conforme a la ley podrán utilizarse como prueba de cargo contra el acusado en el juicio oral. Es más, si en el curso del registro se encontraran efectos u objetos que evidencien la comisión de un delito distinto de aquel para el que se autorizó la entrada y registro podrán recogerse y utilizarse válidamente como prueba de cargo: la jurisprudencia dice que son "hallazgos casuales", frente a los que la autoridad pública que practica el registro no puede cerrar los ojos. ${ }^{23}$

La entrada y registro de edificios o lugares públicos, presenta alguna peculiaridad en cuanto a sus requisitos y su práctica: 1) no siempre es necesario el consentimiento o la autorización para la práctica de esta diligencia, pues en algunos casos basta el mero aviso (arts. 564 y 565 LECrim); 2) en cuanto a la necesidad de auto, salvo en el supuesto de existir causa pendiente, la jurisprudencia admite que se practique sin autorización judicial; 3) la diligencia puede practicarse de día o de noche indistintamente (art. 546 LECrim).

${ }^{23}$ Cfr. stc 41/1998, de 24 de febrero, que legitima los denominados "hallazgos casuales". También, ssts de 7 de junio de 1993 -RA 4849-; 18 de octubre de 1993 -RA 7539-; 29 de junio de 1994 -RA 5163-. 


\section{El registro de libros y papeles}

La diligencia de registro de libros y papeles se regula en los artículos 573 a $578 \mathrm{LECrim}$. El artículo 575 LECrim establece el deber de exhibir los objetos y papeles que puedan tener relación con una causa penal, bajo apercibimiento de multa y eventualmente procesamiento por el delito de desobediencia grave a la autoridad, salvo si quien se negara a ello mereciera la calificación legal de encubridor o receptador.

Además de la exhibición, la LECrim prevé la diligencia de registro de libros y papeles, a cuya práctica se aplicará lo dispuesto en los artículos 552 y 569 relativos al registro domiciliario.

El juez recogerá los libros, papeles o cualesquiera otras cosas que se hubiere encontrado, si esto fuese necesario para el resultado del sumario, siendo foliados, sellados y rubricados en todas sus hojas por el juez, por el secretario, por el interesado o los que hagan sus veces, y por las demás personas que hayan asistido al registro (art. 574 LECrim).

Por último, si el libro que haya de ser objeto del registro fuere el protocolo de un notario, un libro del Registro de la Propiedad o del Registro Civil o Mercantil se estará a lo que disponen las leyes particulares relativas a estos servicios (art. 578 LECrim).

\section{La intervención de las comunicaciones privadas}

La Constitución española garantiza "el secreto de las comunicaciones y, en especial, de las postales, telegráficas y telefónicas [...]” (art. 18.3 CE).

El secreto de las comunicaciones también está expresamente reconocido en la Declaración Universal de Derechos Humanos (DUDH), de 10 de diciembre de 1948, cuyo artículo 12 dispone que "nadie será objeto de injerencias arbitrarias en su vida privada, su familia, su domicilio o su correspondencia. Toda persona tiene derecho a la protección de la Ley contra tales injerencias o ataques”. También aparece reconocido, de forma similar, en el artículo 17 del Pacto Internacional de Derechos Civiles y Políticos (PIDCP), de 16 de diciembre de $1966^{24}$ y en el artículo 8 del Convenio para la Protección de los Derechos Humanos y de las Libertades Fundamentales (СЕDH), hecho en Roma el 14 de noviembre de $1950 .{ }^{25}$

\footnotetext{
${ }^{24}$ El art. 17 del PIDCP dispone: "1. Nadie será objeto de injerencias arbitrarias o ilegales en su vida privada, su familia, su domicilio o su correspondencia, ni de ataques ilegales a su honra y reputación. 2. Toda persona tiene derecho a la protección de la Ley contra esas injerencias".

${ }^{25} \mathrm{El}$ art. 8 del CEDH establece que: "1. Toda persona tiene derecho al respeto de su vida privada y familiar, de su
} 
El secreto de las comunicaciones constituye una garantía del derecho a la vida privada y, en especial, a la intimidad personal. Como ha señalado el Tribunal Constitucional en la sentencia 85/1994, "la observación de las telecomunicaciones supone una grave injerencia en la esfera de la intimidad personal constitucionalmente protegida y como tal injerencia ha de estar sometida al principio de legalidad y, en especial, al de proporcionalidad". ${ }^{26}$ Ello es así porque el derecho a la intimidad personal y familiar consagrado en el artículo 18.4 CE "guarda un estrecho parentesco, por ser una de sus manifestaciones, con el secreto de las comunicaciones y, en especial, de las postales, telegráficas y telefónicas [...] cuya interceptación por tanto significa una 'grave injerencia' en aquél" (sSTc 85/1994 y 34/1996).

Ahora bien, el derecho al secreto de las comunicaciones, como los demás derechos fundamentales, no tiene carácter absoluto sino que puede ser limitado o restringido mediante resolución judicial (art. $18.3 \mathrm{CE}$ ). ${ }^{27}$

\section{A) La intervención de las comunicaciones telefónicas}

La intervención telefónica se configura como una diligencia de investigación adoptada por la autoridad judicial en la fase de instrucción del proceso penal para la captación de las conversaciones mantenidas por el imputado, con el fin de obtener datos que resulten de interés para la investigación de un hecho delictivo determinado. ${ }^{28}$

El artículo 579 LECrim es la única norma legal relativa a la intervención de las comunicaciones telefónicas. Este precepto establece lo siguiente:

domicilio y de su correspondencia. 2. No podrá haber injerencia de la autoridad pública en el ejercicio de este derecho sino en tanto en cuanto esta injerencia esté prevista por la Ley y constituya una medida que, en una sociedad democrática, sea necesaria para la seguridad nacional, la seguridad pública, el bienestar económico del pais, la defensa del orden y la prevención del delito, la protección de la salud o de la moral, o la protección de los derechos y libertades de los demás".

${ }^{26}$ En el mismo sentido, Cfr. SSTC 54/1996; 123/1997 y ATC 344/1990.

${ }^{27}$ Aunque el art. 18.3 CE no menciona el consentimiento del titular como supuesto que legitima la intervención de las comunicaciones - a diferencia de lo que ocurre con el derecho a la inviolabilidad del domicilio (art. $18.2 \mathrm{cE}$ ) - no cabe duda de que el consentimiento enerva la protección constitucional del derecho fundamental al secreto de las comunicaciones.

${ }^{28}$ Sobre la intervención de las comunicaciones telefónicas en el proceso penal, Cfr. Montero ArocA, J., La intervención de las comunicaciones telefónicas en el proceso penal, Valencia, 1999; MontañÉs PARDo, M.A., "La intervención de las comunicaciones. Doctrina jurisprudencial", Cuadernos Aranzadi del Tribunal Constitucional, Pamplona, 1999; López-Barja de Quiroga, J., Escuchas telefónicas y prueba ilegítimamente obtenida, Madrid, 1989; LópezFragoso Álvarez, T., Las intervenciones telefónicas en el proceso penal, Madrid, 1991; Vilaboy Lois, L., y Noya Ferreiro, L., La intervención de las comunicaciones telefónicas en el proceso penal, 2000; GonZÁlez FERnÁnDEZ, J., "LaS intervenciones telefónicas en la jurisprudencia del Tribunal Europeo de Derechos Humanos", Cuadernos de Derecho Judicial, CGP, Madrid, 1993, pp. 327-334; Rodriguez LaInZ, J.L., La intervención de las comunicaciones telefónicas: su evolución en la jurisprudencia del Tribunal Constitucional y del Tribunal Supremo, Barcelona, 2002. 
2. [...] el Juez podrá acordar, en resolución motivada, la intervención de las comunicaciones telefónicas del procesado, si hubiere indicios de obtener por estos medios el descubrimiento o la comprobación de algún hecho o circunstancia importante para la causa.

3. De igual forma, el Juez podrá acordar, en resolución motivada, por un plazo de hasta tres meses, prorrogable por iguales periodos, la observación de las comunicaciones postales, telegráficas o telefónicas de las personas sobre las que existan indicios de responsabilidad criminal, así como de las comunicaciones de las que se sirvan para la realización de sus fines colectivos.

4. En caso de urgencia, cuando las investigaciones se realicen para la averiguación de delitos relacionados con la actuación de bandas armadas o elementos terroristas o rebeldes, la medida prevista en el número 3 de este artículo podrá ordenarla el Ministro del Interior o, en su defecto, el Director de la Seguridad del Estado, comunicándolo inmediatamente por escrito motivado al Juez competente, quien, también de forma motivada, revocará o confirmará tal resolución en un plazo máximo de setenta y dos horas desde que fue ordenada la observación.

Como puede advertirse, se trata de una regulación legal confusa e insuficiente. El artículo 579 LECrim se limita a señalar la posibilidad de que el juez instructor acuerde, en resolución motivada, la intervención u observación de las comunicaciones telefónicas, cuando por este medio se pudiera obtener el descubrimiento o comprobación de algún hecho o circunstancia importante para la causa. Esta norma legal, en cambio, no regula los presupuestos o requisitos básicos que deben concurrir para la autorización de la medida, ni tampoco el procedimiento a seguir.

Ante la insuficiencia de la regulación legal, el régimen jurídico de las denominadas vulgarmente "escuchas telefónicas" ha de buscarse en la doctrina jurisprudencial que, como consecuencia de la deficiente regulación legislativa, se vio obligado a realizar el Tribunal Supremo a partir del auto de 18 de junio de 1992 (RJ 1992/6102). ${ }^{29}$

Conforme a esta doctrina jurisprudencial, la intervención de las comunicaciones telefónicas sólo puede considerarse constitucionalmente legítima cuando, además de estar legalmente prevista con suficiente precisión, se autoriza por la autoridad judicial en el curso de un proceso mediante una decisión suficientemente motivada y se ejecuta con observancia del principio de proporcionalidad; es decir, cuando su autorización se dirige a alcanzar un fin constitucionalmente legítimo, como acontece en los casos en que se adopta para la investigación de

${ }^{29}$ Cfr. Estévez Jimeno, A., "La intervención de las comunicaciones telefónicas. Comentarios y consideraciones acerca

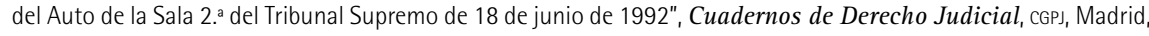
1993 xXIX, pp. 319-324. 
la comisión de delitos calificables de graves y es idónea e imprescindible para la determinación de los hechos relevantes para la misma (sSTc 49/1999, de 5 de abril; 299/2000, de 11 de diciembre; y 184/2003, de 23 de octubre).

La primera cuestión que se plantea es la de si el artículo 579 LECrim constituye habilitación legal suficiente para la restricción del derecho fundamental al secreto de las comunicaciones.

En este sentido, el Tribunal Europeo de Derechos Humanos ha declarado en numerosas ocasiones la vulneración del artículo 8 CEDH porque el actual artículo 579 LECrim, reformado por la Lo 4/1988, de 25 de mayo, no cumple las exigencias requeridas por dicho precepto relativas a la previsión legal de la injerencia. ${ }^{30}$ En efecto, el TEDH desde sus primeras resoluciones (casos Malone y Klass) ha declarado que el requisito establecido en el artículo 8.1 CEDH referido a que la injerencia "esté prevista en la ley" se desglosa en una doble exigencia: que la medida de intervención telefónica se fundamente en el "Derecho interno", esto es, que exista una ley en sentido formal y amplio que prevea la posibilidad de dicha medida y que la norma que la prevea sea asequible al ciudadano -calidad de la ley-, es decir, que las normas sean precisas, claras y detalladas. ${ }^{31}$

Sin embargo, el artículo 579 LECrim no define las categorías de personas sobre las que puede recaer la medida ni la naturaleza de los delitos que justifican la intervención; la regulación del tiempo máximo de la intervención y la posibilidad de sus prórrogas sucesivas hacen absolutamente ilusorio el establecimiento de los límites temporales de la medida y, finalmente, no contiene ninguna referencia a las medidas y precauciones a adoptar para garantizar que las grabaciones efectuadas se comuniquen y trasladen a la autoridad judicial intactas y completas para su eventual control por el juez y la defensa.

También, en nuestro ordenamiento, el propio Tribunal Constitucional ha reconocido que el artículo 579 LECrim adolece de vaguedad e indeterminación en aspectos esenciales, por lo que no satisface los requisitos necesarios exigidos por el artículo 18.3 cE para la protección del derecho al secreto de las comunicaciones, interpretado, como establece el artículo $10.2 \mathrm{cE}$, de acuerdo con

\footnotetext{
${ }^{30}$ Especificamente, el parágrafo 59 de la STEDH de 30 de julio de 1988, en el caso Valenzuela c. España afirmó: "El tribunal señala que algunas de las condiciones que se desprenden del Convenio, necesarias para asegurar la previsibilidad de la ley y garantizar en consecuencia el respeto de la vida privada y de la correspondencia, no están incluidas ni en el art. 18.3 de la Constitución, ni en las disposiciones de la Ley de Enjuiciamiento Criminal, principalmente la definición de las categorias de personas susceptibles de ser sometidas a vigilancia telefónica judicial, la naturaleza de las infracciones que pueden dar lugar a ello, la fijación de un límite de la duración de la ejecución de la medida, las condiciones de establecimiento de los atestados que consignen las conversaciones interceptadas y, la utilización y el borrado de las grabaciones realizadas".

${ }^{31}$ Cfr., entre otras, SSTEDH, de 2 de agosto de 1984, caso Malone c. Reino Unido; 25 de marzo de 1988, caso Kopp c. Suiza; 30 de julio de 1988, caso Valenzuela c. España; 4 de mayo de 2000, caso Rotaru c. Rumania; 24 de abril de 1990, casos Kruslin c. Francia y Huvig c. Francia; 18 de febrero de 2003, caso Prado Bugallo c. España.
} 
el artículo 8.1 y 2 CEDH. En la última sentencia relativa a esta materia, de 23 de octubre de 2003, el tc ha manifestado de forma expresa que el artículo 579 LECrim no es una norma de cobertura adecuada, atendiendo a las garantías de certeza y seguridad jurídica, para la restricción del derecho fundamental al secreto de las comunicaciones telefónicas. ${ }^{32}$

No obstante, considera el Tribunal Constitucional que las deficiencias del artículo 579 LECrim no implican por sí mismas, necesariamente, la ilegitimidad constitucional de las intervenciones telefónicas. En palabras del Tc "si, pese a la inexistencia de una ley que satisficiera las genéricas exigencias constitucionales de seguridad jurídica, los órganos judiciales, a los que el artículo $18.3 \mathrm{CE}$ se remite, hubieran actuado en el marco de la investigación de una infracción grave, para la que de modo patente hubiera sido necesaria, adecuada y proporcionada la intervención telefónica y la hubiesen acordado respecto de personas presuntamente implicadas en el mismo, respetando, además, las exigencias constitucionales dimanantes del principio de proporcionalidad, no cabría entender que el juez hubiese vulnerado, por la sola ausencia de dicha ley, el derecho al secreto de las comunicaciones telefónicas" (STC 49/99 y 184/2003).

En nuestra opinión, sin embargo, a pesar de lo declarado por el тc en la sentencia 49/99 y por el propio ts en el auto de 18 de junio de 1992 y en sentencias posteriores, las deficiencias del artículo 579 LECrim no pueden ser suplidas por vía jurisprudencial, por ser materia reservada a la ley.

Es imprescindible para la legitimidad de la medida que la resolución judicial determine los siguientes extremos:

a) El objeto de la intervención o tipo de delito que ha de ser investigado. No cabe acordar esta medida para el descubrimiento de manera general e indiscriminada de actos delictivos indeterminados. ${ }^{33}$ Por lo tanto, el objeto del control telefónico ha de estar determinado, hasta el punto de que si en el curso de las escuchas telefónicas se descubren datos e informaciones relativos a hechos delictivos que no guardan ninguna relación con la causa investigada, será preciso que la policía dé inmediata cuenta al juez y solicite una ampliación de la autorización para investigar a través de la misma intervención esos nuevos delitos casualmente hallados. ${ }^{34}$ De no hacerse así, las grabaciones obtenidas no servirían como prueba de cargo respecto de esos nuevos delitos.

\footnotetext{
${ }^{32}$ Cfr. sstc 49/99, de 5 de abril y 184/2003, de 23 de octubre.

${ }^{33}$ Cfr., sin ánimo de exhaustividad, ssts 25 de junio de 1993, 11 de octubre de 1994, 10 de marzo de 1995, 22 de julio de 1996, 13 de octubre de 1997, 11 de mayo de 1998 y 23 de septiembre de 1998.

${ }^{34}$ Sobre los denominados por la doctrina alemana "descubrimientos casuales", es decir, conocimientos adquiridos a través de una intervención legítimamente adoptada, pero que no atienden al fin inmediato de la investigación judicial, o afectan a personas respecto a las que no se ha acordado la medida, Vid. ATs de 18 de junio de 1992 y sSTS de 18 de junio de 1993, 8 de julio de 1993, 2 de abril de 1996, 19 de enero de 1998.
} 
Además, las informaciones que se pretendan obtener han de ser de tal trascendencia que por ellas mismas justifiquen la necesidad de injerencia en el derecho fundamental afectado: como ha dicho el ts, sólo cabe la intervención para descubrir delitos de especial gravedad o significación. ${ }^{35}$

b) El número o números de teléfono que han de ser intervenidos.

c) Las personas cuyas conversaciones han de ser interceptadas.

d) Los sujetos encargados de practicar esta diligencia.

e) Los periodos en que deba darse cuenta al juez de instrucción de los resultados de la investigación: el control judicial sobre la aplicación de la medida debe ser riguroso durante el desarrollo y cese de la medida. Este control exige que, mientras se desarrollan las escuchas, el juez reciba información periódica del resultado de las mismas.

En cuanto a la duración de la medida de intervención telefónica, como tiene declarado el TEDH (STEDH de 6 de septiembre de 1978, Caso Klass y otros), la adopción de una escucha telefónica por tiempo indefinido resulta intolerable en un sistema democrático incluso para la salvaguarda de las instituciones. De ahí la necesidad de determinar el plazo máximo durante el cual pueda mantenerse legítimamente una intervención telefónica. El artículo 579.3 LECrim fija un plazo máximo de tres meses, prorrogable por periodos iguales. La prórroga que, en su caso, conceda el juez de instrucción competente deberá adoptar la forma de auto debidamente motivado. Esta motivación no queda cumplida por una remisión a la motivación del auto inicial (sTs de 2 de abril de 1996).

La ejecución de las escuchas telefónicas será encomendada por el órgano jurisdiccional a la policía que se encargará de grabar las conversaciones sostenidas en el número intervenido. Finalizada la investigación, deberán entregarse al juez las cintas originales integras junto con sus transcripciones mecanografiadas, que el secretario compulsará, con el fin de que sea el juez quien seleccione las conversaciones, desechando las que no sean relevantes para la investigación. Asimismo, el juez conservará las cintas magnéticas originales para su posterior audición, siendo posible, en presencia de las partes interesadas (ssts de 22 de enero de 1996; ATs de 28 de febrero de 1996).

\footnotetext{
${ }^{35}$ La Sala Segunda del Tribunal Supremo ha establecido que "una medida de investigación judicial que afecta tan directa y gravemente a la intimidad de las personas... sólo puede encontrar su justificación, en el ámbito del proceso penal, cuando lo que se persiga sea un delito grave" (sts de 6 de febrero de 1995) o "aquellos ilícitos penales en los que las circunstancias concurrentes... aconsejen la utilización y aplicación de medidas tan excepcionales" (sTs de 25 de junio de 1993). Vid., también, ssts 27 de octubre de 1993; 6 de abril de 1994; 12 de enero de 1995; 22 de julio de 1996. entre otras muchas.
} 


\section{B) La intervención de las comunicaciones postales ${ }^{36}$}

$\mathrm{Al}$ igual que para las intervenciones telefónicas, cualquier intervención sobre las comunicaciones postales o telegráficas se adoptará por medio de auto motivado que debe atender al criterio de la proporcionalidad, valorándose entre la gravedad o trascendencia social del hecho a investigar y la injerencia en los derechos al secreto e intimidad de la correspondencia postal reconocidos en la Constitución (arts. 579, 583 LECrim).

La protección constitucional del secreto postal afecta a todos los envíos que puedan facturarse por medio del servicio de correos y, por extensión, por medio de las entidades privadas que ofrezcan análogos servicios: cartas, telegramas, etc. El secreto postal alcanza también a los paquetes postales. ${ }^{37}$

En la resolución se determinará la correspondencia que deba ser detenida o registrada, por medio de la designación de las personas a cuyo nombre se hubieren expedido, o por otras circunstancias igualmente concretas (art. 583 LECrim).

En cuanto a la duración de la medida, el artículo 579.3 LECrim establece un plazo de "hasta tres meses", prorrogable por iguales periodos.

Aunque puede el juez instructor practicar personalmente la detención de la correspondencia, lo usual será que se lleve a cabo por la policía judicial o por el administrador de Correos y Telégrafos o jefe de la oficina en la que se encuentre el envío detenido (art. 580 LECrim). Una vez efectuada la detención, quien la haya realizado remitirá inmediatamente la correspondencia detenida al juez instructor de la causa (art. $581 \mathrm{LECrim)}$.

La correspondencia, o efectos postales retenidos, se abrirán y registrarán en presencia del juez, el secretario y el interesado, que podrá designar quién le represente en esta operación (art. 584 LECrim). La diligencia se practicará leyendo el juez por sí mismo la correspondencia, quien podrá después apartar lo que guarde relación con los hechos de la causa y cuya conservación considere necesaria (art. 586 LECrim). La correspondencia que no se relacione con la causa será entregada en el acto al procesado o a su representante (art. 587 LECrim). Finalmente, se levantará diligencia en la que se hará constar lo ocurrido, la diligencia será firmada por el instructor, el secretario y demás asistentes (art. $588 \mathrm{LECrim)}$.

\footnotetext{
${ }^{36} \mathrm{Cfr}$. MONTERo ArocA, J., Detención y apertura de la correspondencia y de los paquetes postales en el proceso penal, Valencia, 2000 y Vegas TorRES, J., "Detención y apertura de paquetes postales. Especial consideración de la apertura de paquetes en el marco de las entregas vigiladas", Tribunales de Justicia, No. 8-9, 1997, pp. 849-864. ${ }^{37}$ Sobre la inclusión de los paquetes postales en la garantía constitucional del secreto de las comunicaciones, Vid. el acuerdo alcanzado en la Reunión General de la Sala Segunda del Tribunal Supremo de 4 de abril de 1995, ratificado por otro adoptado en la Reunión Plenaria, de 17 de enero de 1996.
} 